Published in final edited form as:

Prim Care Diabetes. 2011 July ; 5(2): 95-102. doi:10.1016/j.pcd.2011.02.002.

\title{
$\mathrm{HbA}_{1 \mathrm{c}}$ Values for Defining Diabetes and Impaired Fasting Glucose in Asian Indians
}

\author{
Manisha Nair, \\ Fogarty International Centre \& Centre of Excellence-Centre for Cardiometabolic Risk Reduction \\ in South Asia, Public Health Foundation of India, New Delhi, India
}

Dorairaj Prabhakaran,

Public Health Foundation of India and Centre for Chronic Disease Control, New Delhi, India

\author{
K.M. Venkat Narayan, \\ Emory University, Atlanta, USA
}

\section{Rashmi Sinha,}

Nutritional Epidemiology Branch, Division of Cancer Epidemiology and Genetics, National Cancer Institute, NIH, MD, USA

\section{Ramakrishna Lakshmy, Department of Cardiac Biochemistry, All India Institute of Medical Sciences (AIIMS), New Delhi, India}

\section{Niveditha Devasenapathy, Indian Institute of Public Health, Delhi, India}

\section{Carrie R. Daniel,}

Nutritional Epidemiology Branch, Division of Cancer Epidemiology and Genetics, National Cancer Institute, NIH, MD, USA

\section{Ruby Gupta,}

Department of Cardiac Biochemistry, All India Institute of Medical Sciences (AlIMS), New Delhi, India

\section{Preethi S. George,}

Regional Cancer Centre, Thiruvananthapuram, India

\author{
Aleyamma Mathew, \\ Regional Cancer Centre, Thiruvananthapuram, India
}

Nikhil Tandon, and

Dept of Endocrinology \& Metabolism, All India Institute of Medical Sciences, New Delhi, India

\section{K. Srinath Reddy \\ Public Health Foundation of India, New Delhi, India}

Manisha Nair: dr.manisha.das@gmail.com; Dorairaj Prabhakaran: dprabhakaran@ccdcindia.org; K.M. Venkat Narayan: knaraya@emory.edu; Rashmi Sinha: sinhar@exchange.nih.gov; Ramakrishna Lakshmy: lakshmy_ram@yahoo.com; Niveditha Devasenapathy: niveditha@iiphd.org; Carrie R. Daniel: danielc3@mail.nih.gov; Ruby Gupta:

\footnotetext{
(C) 2011 Elsevier Ltd. All rights reserved.

Conflicts of interest: The authors state that there are no conflicts of interest with regards to this study.

Publisher's Disclaimer: This is a PDF file of an unedited manuscript that has been accepted for publication. As a service to our customers we are providing this early version of the manuscript. The manuscript will undergo copyediting, typesetting, and review of the resulting proof before it is published in its final citable form. Please note that during the production process errors may be discovered which could affect the content, and all legal disclaimers that apply to the journal pertain.
} 
g_ruby2123@yahoo.co.in; Preethi S. George: preethig@rcctvm.org; Aleyamma Mathew: amathew@rcctvm.org; Nikhil Tandon: nikhil_tandon@hotmail.com; K. Srinath Reddy: ksrinath.reddy@phfi.org

\section{Background}

Glycated haemoglobin (HbA1c) serves as an established measure of glucose control in people with diabetes and is a measure of the degree of exposure to glucose over a cumulative period of time. As standardisation has improved [1], there is renewed interest in the potential to use $\mathrm{HbA}_{1 \mathrm{c}}$ to diagnose diabetes, and an international expert committee (IEC) in 2009 proposed a $\mathrm{HbA}_{1 \mathrm{c}}$ level of $\geq 6.5 \%$ for diagnosing diabetes and $\geq 6.0 \%$ for diagnosing impaired glycaemic states[2]. In the following year, 2010, American Diabetes Association (ADA) officially recognised $\mathrm{HbA}_{1 \mathrm{c}}$ as a diagnostic test recommending cut-points $\geq 6.5 \%$ for diabetes and $5.7 \%$ to $6.4 \%$ for high risk groups $[3,4]$.

However, there is considerable debate about the $\mathrm{HbA}_{1 \mathrm{c}}$ cut-points [5-8]. Studies in different population groups throughout the world to assess the appropriateness of the recommended $\mathrm{HbA}_{1 \mathrm{c}}$ values have suggested cut-points for diabetes ranging from $\geq 5.6 \%$ to $\geq 7.0 \%$ [5, 9-12]. Age, ethnicity, genetic make-up, erythrocyte life-span and erythrocyte environment all may contribute to inter-individual and inter-group variability of glycosylation of haemoglobin $[2,7,9,12-17]$ and thus to differences in the cut-points.

Three published regional studies from India, a country with very high and growing prevalence of diabetes, have suggested $\mathrm{HbA}_{1 \mathrm{c}}$ cut-points for Southern and Northern Indian populations. In a study conducted in 1998 by Snehalatha et.al, a $\mathrm{HbA}_{1 \mathrm{c}}$ cut-point of $\geq 6.0 \%$ was found to be highly sensitive and specific in detecting diabetes [18], whereas Mohan et.al. in the same city of Chennai found a cut-point of $\geq 6.4 \%$ to be more appropriate [19]. Another recently published study found a cut-point of $\geq 6.1 \%$ to be optimally sensitive and specific for detecting diabetes in a study population in Chandigarh in Northern India [20]. Given the geographical and ethnic diversity of India, clearly more data are needed to elucidate cut-points suitable for Indian populations. Utilising blood samples collected in a cohort study conducted in Northern (New Delhi) and Southern (Trivandrum) regions of India, we describe the normative distribution of $\mathrm{HbA}_{1 \mathrm{c}}$ and explore cut-points for defining diabetes and high-risk for diabetes.

\section{Methods}

Our study population was selected randomly from the India Health Study participants (IHS; $\mathrm{n}=4,000$ ), conducted in three cities in India (New Delhi, Trivandrum and Mumbai) and completed in 2008. Details about the IHS is described elsewhere [21], briefly, the IHS was conducted between December 2006 and July 2008 with the primary objective of assessing the feasibility of establishing a prospective cohort in India to facilitate studies on incidence of cancer, cardiovascular diseases and other non-communicable diseases, and their risk factors; such as the patterns of eating and dietary habits in the Indian context. The sampling method was random and stratified by gender, religion and type of residence (urban/rural) and was powered to calculate the mean of various food and nutrient intake in each strata of the sample population. Pregnant women and people with previous history of cancer or cardiovascular event were not included in the study. The participants included mostly middle-class adults, aged 35 to 69 years who provided consent to participate and provide biological samples for the study. However, no biological samples were collected in Mumbai, due to inadequate laboratory resources and storage facilities in that area. $\mathrm{HbA}_{1 \mathrm{c}}$ measurements were conducted in a random sample of 525 individuals from the 3280 IHS participants in New Delhi and Trivandrum who provided fasting blood samples. The 525 participants included in this study were not statistically significantly different from the 
remaining population in terms of their mean fasting plasma glucose, and were comparable in age and body mass index (BMI); however, those excluded from the study had a smaller waist and hip circumference compared to those included. Further, the sample excluded had a statistically significant higher prevalence of diabetes both known (13.9\%) and Newly Diagnosed Diabetes (NDD) (12.8\%) compared to those included (known diabetes $=12.4 \%$ and NDD $=10.2 \%$ ), but comparatively lower prevalence of IFG (shown in Table-1). The comparatively lower prevalence of known diabetes and NDD in the sample population for this study, therefore, rules out the possibility of selection bias.

\section{Definition and construct of the variable for glycaemic status}

Based on subjective history, 64 people were classified as known diabetes. For the remaining 461 , we used fasting plasma glucose (FPG) to classify participants as normal fasting glucose (NFG), impaired fasting glucose (IFG) and newly diagnosed diabetes (NDD) using both American Diabetes Association (ADA) and World Health Organization (WHO) criteria. As per ADA, normal was defined as FPG $<100 \mathrm{mg} / \mathrm{dl}(<5.6 \mathrm{mmol} / \mathrm{l})$, IFG as FPG between 100 and $125 \mathrm{mg} / \mathrm{dl}(5.6-7.0 \mathrm{mmol} / \mathrm{l})$ and newly diagnosed diabetes (NDD) as FPG $\geq 126 \mathrm{mg} / \mathrm{dl}$ $(\geq 7.0 \mathrm{mmol} / \mathrm{l})[22]$. Using the definition of WHO, participants with FPG $<110 \mathrm{mg} / \mathrm{dl}$ $(<6.1 \mathrm{mmol} / \mathrm{l})$ were defined as normal, those having FPG between 110 and $125 \mathrm{mg} / \mathrm{dl}$ (6.1-7.0mmol/l) as IFG and those with FPG $\geq 126 \mathrm{mg} / \mathrm{dl}(\geq 7.0 \mathrm{mmol} / \mathrm{l})$ as NDD [23].

\section{Laboratory methods}

Blood samples $(15 \mathrm{ml})$ from the participants were collected after an overnight fast. Fasting plasma glucose (FPG) was estimated by the glucose oxidase / peroxidase method [24] (Delhi: GOD-PAP; Randox Laboratories Ltd., Antrim, UK; Trivandrum: GOD-POD; Autospan; Span Diagnostics Ltd., Surat, India). $\mathrm{HbA}_{1 \mathrm{c}}$ was measured on SYNCHRON CX 5 using reagents from BECKMAN COULTER. The system uses two cartridges, one for haemoglobin and one for $\mathrm{A}_{1 \mathrm{c}}$. Haemoglobin reagent is used to measure total haemoglobin concentration by a colorimetric method. One part of sample is mixed with 8.6 parts of reagent automatically. Change in absorbance which is directly proportional to concentration of total haemoglobin is measured at $410 \mathrm{~nm}$. $A_{1 c}$ reagent is used to measure the haemoglobin $\mathrm{A}_{1 \mathrm{c}}$ concentration by a turbidimetric immune-inhibition method. In the reaction, $\mathrm{HbA}_{1 \mathrm{c}}$ antibodies combine with $\mathrm{HbA}_{1 \mathrm{c}}$ from sample to form soluble antigen antibody complexes. Polyhaptens from the reagent then bind with the excess antibodies and the resulting agglutinated complex is measured tubidimetrically at $340 \mathrm{~nm}$. The final result is reported as percentage (\%) $\mathrm{HbA}_{1 \mathrm{c}}$ automatically and is calculated as $\mathrm{A}_{1 \mathrm{c}}(\mathrm{g} / \mathrm{dl}) \times 100 / \mathrm{Hb}$ $(\mathrm{g} / \mathrm{dl})$.

\section{Statistical analysis}

All statistical analyses were performed using STATA version 10.1. We described the study population in terms of their clinical, anthropometric and bio-chemical characteristics using means and standard errors (SE). Bivariate associations between continuous variables and the categories of glycaemic states were determined using ANOVA with Scheffe's multiple comparison tests. Pearson's correlation co-efficient was used to analyse the correlation between $\mathrm{HbA}_{1 \mathrm{c}}$ and FPG among unknown diabetes participants. All statistical associations were considered to be significant with a two-sided p-value less than 0.05 . There were 64 participants with a history of diabetes and were on medication; hence, $\mathrm{HbA}_{1 \mathrm{c}}$ cut-points were calculated for NDD and IFG. Receiver Operating Characteristics curves (ROC) were used to identify the optimum sensitivity and specificity with $95 \%$ confidence interval (CI) for defining the $\mathrm{HbA}_{1 \mathrm{c}}$ cut-points against the FPG criteria using both the ADA and the WHO. The Area Under Curve (AUC) was constructed and the point closest to the upper-left corner with maximum sensitivity and specificity was selected as the optimal cut point [25]. Sensitivity was defined as the proportion of participants with IFG or diabetes who were 
identified correctly by a $\mathrm{HbA}_{1 \mathrm{c}}$ value greater than or equal to the cut point. Specificity was defined as the proportion of participants without IFG and diabetes who were correctly identified by a $\mathrm{HbA}_{1 \mathrm{c}}$ value less than the cut point. Positive predictive value (PPV), negative predictive value (NPV) and accuracy for defining diabetes and IFG with their 95\% CI were estimated for each cut-point of $\mathrm{HbA}_{1 \mathrm{c}}$. We also estimated the proportion of subjects without known diabetes who would be classified as NFG, IFG and NDD at different cut-points of $\mathrm{HbA}_{1 \mathrm{c}}$.

\section{Results}

The mean FPG was $105.1( \pm 1.37) \mathrm{mg} / \mathrm{dl}$ for participants without known history of diabetes. Based on ADA and WHO criteria respectively, $44.9 \%$ (95\% CI 40.3\%-49.6\%) and 71.4\% (95\% CI $67.0 \%-75.5 \%$ ) were NFG, and $44.7 \%$ (95\% CI 40.1\%-49.4\%) and $18.2 \%$ (95\% CI 14.8\%-22.1) had IFG. Overall prevalence of diabetes (both known and NDD) in the study population was 21.3 (95\% CI 17.9\%-25.1\%), $12.2 \%$ (95\% CI 9.5\%-15.3\%) had a known history of diabetes and $10.4 \%$ (95\% CI 7.8\%-13.6\%) were NDD. Table-2 describes the study population characteristics stratified by their glycaemic states: $44.5 \%$ were males and $55.4 \%$ females. Mean $\mathrm{HbA}_{1 \mathrm{c}}$ was $5.4( \pm 0.04) \%, 5.7( \pm 0.06) \%, 5.8( \pm 0.09) \%, 7.5( \pm 0.33) \%$ and $8.4( \pm 0.32) \%$ in participants with NFG, IFG (ADA), IFG(WHO), NDD and known diabetes respectively. The correlation (Pearson's correlation co-efficient) between $\mathrm{HbA}_{1 \mathrm{c}}$ and FPG for participants without known history of diabetes was 0.61 ( $\mathrm{p}<0.001)$ (Fig-1), but varied across the different glycaemic strata. According to WHO criteria, the correlation between $\mathrm{HbA}_{1 \mathrm{c}}$ and NFG was 0.15 ( $\left.\mathrm{p}=0.006\right)$, IFG $0.27(\mathrm{p}=0.008)$ and NDD $0.61(\mathrm{p}<0.001)$, which was similar to the ADA criteria: NFG $0.10(\mathrm{p}=0.13)$, IFG $0.23(\mathrm{p}=0.001)$ and NDD $0.61(\mathrm{p}<0.001)$.

Table-3 shows the ROC results for $\mathrm{HbA}_{1 \mathrm{c}}$ cut-points evaluated against FPG criteria (both ADA and WHO) for participants with unknown diabetes. The optimal $\mathrm{HbA}_{1 \mathrm{c}}$ cut-point for NDD using FPG $\geq 126 \mathrm{mg} / \mathrm{dl}$ was $5.8 \%$ with a sensitivity of $75 \%$, specificity of $75.4 \%$ and an area under curve (AUC) of 0.819 . For IFG (ADA criteria) a cut-point of $5.5 \%$ had the optimum sensitivity (59.7\%) and specificity (59.9\%) with an AUC of 0.627. For IFG (WHO criteria) a cut-point of $5.6 \%$ was found to have the optimum sensitivity $(60.7 \%)$ and specificity (65.1\%) with an AUC of 0.671 . The $\mathrm{HbA}_{1 \mathrm{c}}$ cut-point of $\geq 5.5 \%$ would correctly identify $70.2 \%$ and $59.7 \%$ of the participants with IFG using WHO and ADA criteria, respectively (Table-4). The cut-point of $\geq 5.8 \%$ would correctly identify $75 \%$ of participants with diabetes, however $42.9 \%$ and $33.5 \%$ of participants with IFG (using WHO and ADA criteria, respectively), and $19.8 \%$ and $15.5 \%$ of normal participants (using WHO and ADA criteria respectively) will also be included (Table-4). Although using the currently recommended $\mathrm{HbA}_{1 \mathrm{c}}$ level of $\geq 6.5 \%$ decreases the proportion of false positives, the proportion with diabetes identified correctly (true positives) decreases by $21 \%$ in absolute terms (Table-4).

\section{Discussion}

There was a high prevalence of diabetes (FPG $\geq 126 \mathrm{mg} / \mathrm{dl}$ ) in the study population with $10.4 \%$ being newly diagnosed. The optimal $\mathrm{HbA}_{1 \mathrm{c}}$ cut-points for NDD $(\geq 5.8 \%)$ and IFG $(\geq 5.5 \% / \geq 5.6 \%)$ was considerably lower than those recommended by the IEC ( $\geq 6.5 \%$ for diabetes and $\geq 6.0 \%$ for IFG) [2] and the ADA ( $\geq 6.5 \%$ for diabetes and $\geq 5.7 \%$ for high risk groups) [3, 4]. Our results, however, are consistent with other studies conducted across the world, which have found values lower than the recommended levels for diabetes: $5.8 \%$ in the Dutch population [9], 6.1\%, 5.6\% and 6.3\% in Chinese population [5, 11, 26], 5.7\% in the US population [10], $\geq 5.6 \%$ in Japanese population (Funagata study) [27] and $\geq 6.0 \%$ in an American population in Pittsburgh and Memphis [13]. We found a low sensitivity and 
specificity, and low AUC for $\mathrm{HbA}_{1 \mathrm{c}}$ cut-point for IFG using FPG criterion. However several studies suggest that $\mathrm{HbA}_{1 \mathrm{c}}$ is not sensitive for screening of IFG [2, 5]. A systematic review of nine studies (six European and three Asian) published between 1998 and 2004 found $\mathrm{HbA}_{1 \mathrm{c}} \geq 6.1 \%$ and $\geq 6.2 \%$ to be optimal for the detection of diabetes, but sensitivity of $\mathrm{HbA}_{1 \mathrm{c}}$ for detecting impaired glycaemic states was in general low across the studies [28].

In the context of India, our study cut-point of $\geq 5.8 \%$ for diabetes is lower than those of Snehalatha et.al. (study conducted in 1998) and Kumar et.al (study conducted in 2008-09) who found a $\mathrm{HbA}_{1 \mathrm{c}}$ cut-point of $\geq 6.0 \%$ and $\geq 6.1 \%$ to be optimally sensitive and specific for detecting NDD in South Indian and North Indian population groups respectively [18, 20]. However, our study results compare and contrast the findings of the study by Mohan et.al. While the $\mathrm{HbA}_{1 \mathrm{c}}$ cut-point for IFG using FPG criterion was the same (5.6\%), we found a much lower cut-point for NDD (5.8\%) compared to Mohan et.al. (6.4\%) using the same FPG $\geq 126 \mathrm{mg} / \mathrm{dl}$ criterion [19], but the AUC in general were lower in our study. The demographic and biochemical characteristics of the study participants were different from that of the participants in Mohan et.al's Chennai Urban Rural Epidemiological Study (CURES). Our study participants were older and had a higher body mass index (BMI) compared to CURES. The laboratory analysis method for $\mathrm{HbA}_{1 \mathrm{c}}$ used in CURES was High Performance Liquid Chromatography (HPLC) and that used in the IHS was Immunoturbidimetry [19] and both instruments are NGSP (National Glycohaemoglobin Standardisation Programme) certified.

Results of two studies from different population groups in China, Hong Kong Chinese and Chinese Han in Shanghai, have found different cut-points of $\mathrm{HbA}_{1 \mathrm{c}}$ for diabetes 5.5\% [29] and 6.1\% respectively[5]. Two other recent studies in China, in Shanghai (2007-08) and Qingdao (2006), suggested cut-points of $\geq 6.3 \%$ and $\geq 5.6 \%$ to have optimal sensitivity and specificity for detecting NDD $[11,26]$. This is plausible considering the inter-individual variability in the amount of glycosylation and the diversity in population characteristics. This suggests that apart from inter-nation variability in the distribution of normative $\mathrm{HbA}_{1 \mathrm{c}}$ levels, the intra-nation variability found by studies on different population groups within countries like India and China could further add to the complexity of identifying a common $\mathrm{HbA}_{1 \mathrm{c}}$ cut-point.

Recently, a number of studies across the world that have examined the concordance between glucose-based criteria (FPG, Oral Glucose Tolerance Test-OGTT) and $\mathrm{HbA}_{1 \mathrm{c}}$ criterion for screening of diabetes, suggests that there is significant discordance between glucose-based and the recommended $\mathrm{HbA}_{1 \mathrm{c}}(\geq 6.5 \%)$ criteria which is further accentuated by age, gender and race [13,30-34]. An editorial by Cohen et.al. summaries the existing empirical evidence of this inter-individual variability and in the light of these, further reiterates the need for studies in composite population groups representative of the prevailing diversities for effective utilization of $\mathrm{HbA}_{1 \mathrm{c}}$ [35].

The correlation between $\mathrm{HbA}_{1 \mathrm{c}}$ and FPG was fairly high (0.61) in the study population which may be attributed to the high prevalence of diabetes. Our results are, however, comparable to results reported by Snehalatha et.al. in Southern India ( $r=0.82)$ [18], a retrospective analysis of data of type-II diabetes patients living in Oman ( $\mathrm{r}=0.62)$ [36], and the Atherosclerosis Risk in Communities (ARIC) study ( $\mathrm{r}=0.73$ ) [37] conducted in the U. S. African Americans have also reported remarkably similar correlations. Conversely, a study conducted on Dutch population comprising of participants from the New Hoorn Study [9] showed only a moderate correlation $(\mathrm{r}=0.46)$.

Given the limitations of $\mathrm{HbA}_{1 \mathrm{c}}$ as a screening test in non-diabetes individuals, researchers have attempted to identify methods to improve its efficacy. A study using the NHANES 
1999-2004 data showed that $\mathrm{HbA}_{1 \mathrm{c}}$ as a screening test may have higher predictive validity in subjects who are stratified according to their risk factors for diabetes [38]. A Swedish population-based study showed that the combination of $\mathrm{HbA}_{1 \mathrm{c}}$, FPG and $\mathrm{BMI}$ is more sensitive and specific than $\mathrm{HbA}_{1 \mathrm{c}}$ alone and has a high PPV for screening of type 2 diabetes [39]. Again studies among Korean and Chinese adults suggest that a combination of $\mathrm{HbA}_{1 \mathrm{c}}$ and FPG can detect a greater proportion of NDD compared to each of these tests alone [30, 40]. Other studies suggest that performing a test for FPG followed by $\mathrm{HbA}_{1 \mathrm{c}}$ estimation in selected patients who are at risk of developing diabetes can minimize the requirement of OGTT, which can be both time consuming and inconvenient to patients [41-45]. UK department of Health recommends a coupled algorithm of $\mathrm{HbA}_{1 \mathrm{c}}$ and OGTT for screening of diabetes. Individuals who are found to have $\mathrm{HbA}_{1 \mathrm{c}}$ between $6 \%$ and $6.4 \%$ undergo OGTT to confirm the presence of diabetes [46].

In the IHS study two hour plasma glucose (2-hPG) test was not done, hence the glycaemic states and $\mathrm{HbA}_{1 \mathrm{c}}$ for the study population was based on the FPG criteria alone. It is thus possible that we might have missed a group with normal FPG but elevated 2-hPG.

Moreover, apart from being a single test, the results of FPG are more reproducible than 2hPG and considered to be as good a predictor of glycaemic status for unknown diabetes as 2-hPG [5, 47, 48].

\section{Conclusion}

Our findings contribute to the debate on appropriate international cut-points for $\mathrm{HbA}_{1 \mathrm{c}}$ and its potential value as a screening tool. The possible roles of age, race, genetic make-up, erythrocyte life-span and erythrocyte environment which contribute to the inter-individual variability of glycosylation of haemoglobin $[2,9,13,14,16]$ may be more heterogeneous in the Indian sub-continent. We found a lower $\mathrm{HbA}_{1 \mathrm{c}}$ cut-point for diabetes than that reported in the three studies conducted in South and North Indian population groups and than is currently recommended by IEC and ADA [2,3]. There is a need for larger population-based studies comprised of composite population groups from different regions of the country in order to draw a consensus on the normative value of $\mathrm{HbA}_{1 \mathrm{c}}$ for Asian Indians. Further, Asian Indians being a highly heterogeneous community will provide a greater scope for researchers to understand the determinants of $\mathrm{HbA}_{1 \mathrm{c}}$ responsible for inter-individual glycation of haemoglobin and thereby, the different observed relationships between $\mathrm{HbA}_{1 \mathrm{c}}$ and glycaemia.

\section{References}

1. Hanas R, John G. on behalf of the International HbA1c Consensus Committee. 2010 Consensus Statement on the Worldwide Standardization of the Hemoglobin A1c Measurement. Clin Chem. 2010 August 1; 56(8):1362-4. [PubMed: 20508083]

2. International Expert Committee Report on the Role of the A1C Assay in the Diagnosis of Diabetes. Diabetes Care. 2009 July; 32(7):1327-34. [PubMed: 19502545]

3. American Association of Clinical Endocrinologists/American College of Endocrinology statement on the use of hemoglobin A1c for the diagnosis of diabetes. Endocr Pract. 2010 Mar-Apr; 16(2): 155-6. [PubMed: 20350901]

4. Hill AN, Appel SJ. Diagnosing diabetes with A1C: implications and considerations for measurement and surrogate markers. Nurse Pract. 2010 Oct; 35(10):16-23. [PubMed: 20827232]

5. Hu Y, Liu W, Chen Y, Zhang M, Wang L, Zhou H, et al. Combined use of fasting plasma glucose and glycated hemoglobin A1c in the screening of diabetes and impaired glucose tolerance. Acta Diabetol. 2009 Sep 17.

6. Kilpatrick ES. Haemoglobin A1c in the diagnosis and monitoring of diabetes mellitus. J Clin Pathol. 2008 September 1 2008; 61(9):977-82. [PubMed: 18755721] 
7. Lippi G, Targher G. Glycated hemoglobin (HbA1c): old dogmas, a new perspective? Clin Chem Lab Med. 2010 May; 48(5):609-14. [PubMed: 20464776]

8. Bloomgarden ZT. A1C: Recommendations, Debates, and Questions. Diabetes Care. 2009 December 1 2009; 32(12):e141-e7. [PubMed: 19940210]

9. Van't Riet E, Alssema M, Rijkelijkhuizen JM, Kostense PJ, Nijpels G, Dekker JM. The relationship between HbA1c and glucose levels in the general Dutch population: The new Hoorn study. Diabetes Care. 2009 Oct 6.

10. Rohlfing CL, Little RR, Wiedmeyer HM, England JD, Madsen R, Harris MI, et al. Use of GHb (HbA1c) in screening for undiagnosed diabetes in the U.S. population. Diabetes Care. 2000 Feb; 23(2):187-91. [PubMed: 10868829]

11. Bao Y, Ma X, Li H, Zhou M, Hu C, Wu H, et al. Glycated haemoglobin A1c for diagnosing diabetes in Chinese population: cross sectional epidemiological survey. BMJ. 340

12. Davidson MB, Schriger DL. Effect of age and race/ethnicity on HbA1c levels in people without known diabetes mellitus: Implications for the diagnosis of diabetes. Diabetes Research and Clinical Practice. 2010; 87(3):415-21. [PubMed: 20061043]

13. Lipska KJ, De Rekeneire N, Van Ness PH, Johnson KC, Kanaya A, Koster A, et al. Identifying dysglycemic states in older adults: implications of the emerging use of hemoglobin A1c. J Clin Endocrinol Metab. 2010 Dec; 95(12):5289-95. [PubMed: 20861123]

14. Soranzo N, Sanna S, Wheeler E, Gieger C, Radke D, Dupuis J, et al. Common Variants at 10 Genomic Loci Influence Hemoglobin A1C Levels via Glycemic and Nonglycemic Pathways. Diabetes. 2010 December 1; 59(12):3229-39. [PubMed: 20858683]

15. Jorgensen ME, Bjerregaard P, Borch-Johnsen K, Witte D. New Diagnostic Criteria for Diabetes: Is the Change from Glucose to HbA1c Possible in All Populations? J Clin Endocrinol Metab. 2010 November 1; 95(11):E333-6. [PubMed: 20739381]

16. Vandewiele A, Genbrugge K, Delanghe J. Spuriously high HbA1c due to the presence of haemoglobin Raleigh: a case report and review of the literature. Acta Clin Belg. 2010 Sep-Oct; 65(5):336-40. [PubMed: 21128561]

17. Kilpatrick ES, Bloomgarden ZT, Zimmet PZ. Is haemoglobin A1c a step forward for diagnosing diabetes? BMJ. 339

18. Snehalatha C, Ramachandran A, Satyavani K, Vijay V. Limitations of glycosylated haemoglobin as an index of glucose intolerance. Diabetes Res Clin Pract. 2000 Feb; 47(2):129-33. [PubMed: 10670913]

19. Mohan V, Vijayachandrika V, Gokulakrishnan K, Anjana RM, Ganesan A, Weber MB, et al. $\mathrm{HbA1c}$ cut points to define various glucose intolerance groups in Asian Indians. Diabetes Care. 2009 November 10.

20. Kumar PR, Bhansali A, Ravikiran M, Bhansali S, Dutta P, Thakur JS, et al. Utility of Glycated Hemoglobin in Diagnosing Type 2 Diabetes Mellitus: A Community-Based Study. J Clin Endocrinol Metab. 2010 June 1; 95(6):2832-5. [PubMed: 20371663]

21. Daniel C, Prabhakaran D, Kapur K, Graubard B, Devasenapathy N, Ramakrishnan L, et al. A cross-sectional investigation of regional patterns of diet and cardio-metabolic risk in India. Nutrition Journal. 2011; 10(1):12. [PubMed: 21276235]

22. American Diabetes Association. Standards of medical care in diabetes-2007. Diabetes Care. 2007; 30:S4-S41. [PubMed: 17192377]

23. World Health Organization. Definition and Diagnosis of Diabetes Mellitus and Intermediate Hyperglycemia: Report of a WHO/IDF Consultation. Geneva: World Health Org.; 2006.

24. Lott JA, Turner K. Evaluation of Trinder's Glucose Oxidase Method for Measuring Glucose in Serum and Urine. Clin Chem. 1975 November 1; 21(12):1754-60. [PubMed: 1237363]

25. Hanley JA, McNeil BJ. The meaning and use of the area under a receiver operating characteristic (ROC) curve. Radiology. 1982; 143:29-36. [PubMed: 7063747]

26. Zhou X, Pang Z, Gao W, Wang S, Zhang L, Ning F, et al. Performance of an A1C and Fasting Capillary Blood Glucose Test for Screening Newly Diagnosed Diabetes and Pre-Diabetes Defined by an Oral Glucose Tolerance Test in Qingdao, China. Diabetes Care. 2010 March 1; 33(3):54550. [PubMed: 20007941] 
27. Nakagami T, Tominaga M, Nishimura R, Yoshiike N, Daimon M, Oizumi T, et al. Is the measurement of glycated hemoglobin A1c alone an efficient screening test for undiagnosed diabetes? Japan National Diabetes Survey. Diabetes Res Clin Pract. 2007 May; 76(2):251-6. [PubMed: 17049661]

28. Bennett CM, Guo M, Dharmage SC. HbA(1c) as a screening tool for detection of Type 2 diabetes: a systematic review. Diabet Med. 2007 Apr; 24(4):333-43. [PubMed: 17367307]

29. Ko GT, Chan JC, Yeung VT, Chow CC, Tsang LW, Li JK, et al. Combined use of a fasting plasma glucose concentration and HbA1c or fructosamine predicts the likelihood of having diabetes in high-risk subjects. Diabetes Care. 1998 Aug; 21(8):1221-5. [PubMed: 9702423]

30. Kim CH, Kim HK, Bae SJ, Park JY, Lee KU. Discordance between fasting glucose-based and hemoglobin A1c-based diagnosis of diabetes mellitus in Koreans. Diabetes Research and Clinical Practice. 2011; 91(1):e8-e10. [PubMed: 20970868]

31. Rathmann W, Kowall B, Tamayo T, Giani G, Holle R, Thorand B, et al. Hemoglobin A1c and glucose criteria identify different subjects as having type 2 diabetes in middle-aged and older populations: The KORA S4/F4 Study. Annals of Medicine. 0(0):1-8.

32. Olson DE, Rhee MK, Herrick K, Ziemer DC, Twombly JG, Phillips LS. Screening for Diabetes and Pre-Diabetes With Proposed A1C-Based Diagnostic Criteria. Diabetes Care. 2010 October 1; 33(10):2184-9. [PubMed: 20639452]

33. Cowie CC, Rust KF, Byrd-Holt DD, Gregg EW, Ford ES, Geiss LS, et al. Prevalence of Diabetes and High Risk for Diabetes Using A1C Criteria in the U.S. Population in 1988-2006. Diabetes Care. 2010 March 1; 33(3):562-8. [PubMed: 20067953]

34. Christensen DL, Witte DR, Kaduka L, Jørgensen ME, Borch-Johnsen K, Mohan V, et al. Moving to an A1C-Based Diagnosis of Diabetes Has a Different Impact on Prevalence in Different Ethnic Groups. Diabetes Care. 2010 March 1; 33(3):580-2. [PubMed: 20009099]

35. Cohen RM, Haggerty S, Herman WH. HbA1c for the Diagnosis of Diabetes and Prediabetes: Is It Time for a Mid-Course Correction? J Clin Endocrinol Metab. 2010 December 1; 95(12):5203-6. [PubMed: 21131541]

36. Al-Lawati JA, Al-Lawati AM. The utility of fasting plasma glucose in predicting glycosylated hemoglobin in type 2 diabetes. Ann Saudi Med. 2007 Sep-Oct; 27(5):347-51. [PubMed: 17921686]

37. Selvin E, Steffes MW, Zhu H, Matsushita K, Wagenknecht L, Pankow J, et al. Glycated Hemoglobin, Diabetes, and Cardiovascular Risk in Nondiabetic Adults. NEJM. 2010; 362(9):80111.

38. Ginde AA, Cagliero E, Nathan DM, Camargo CA Jr. Value of risk stratification to increase the predictive validity of $\mathrm{HbA} 1 \mathrm{c}$ in screening for undiagnosed diabetes in the US population. J Gen Intern Med. 2008 Sep; 23(9):1346-53. [PubMed: 18543044]

39. Norberg M, Eriksson JW, Lindahl B, Andersson C, Rolandsson O, Stenlund H, et al. A combination of $\mathrm{HbA1c}$, fasting glucose and BMI is effective in screening for individuals at risk of future type 2 diabetes: OGTT is not needed. J Intern Med. 2006 Sep; 260(3):263-71. [PubMed: $16918824]$

40. Hu Y, Liu W, Chen Y, Zhang M, Wang L, Zhou H, et al. Combined use of fasting plasma glucose and glycated hemoglobin A1c in the screening of diabetes and impaired glucose tolerance. Acta Diabetologica. 2010; 47(3):231-6. [PubMed: 19760291]

41. Geberhiwot T, Haddon A, Labib M. HbA1c predicts the likelihood of having impaired glucose tolerance in high-risk patients with normal fasting plasma glucose. Ann Clin Biochem. 2005 May; 42(Pt 3):193-5. [PubMed: 15949153]

42. Wang W, Lee ET, Fabsitz R, Welty TK, Howard BV. Using HbA(1c) to improve efficacy of the american diabetes association fasting plasma glucose criterion in screening for new type 2 diabetes in American Indians: the strong heart study. Diabetes Care. 2002 Aug; 25(8):1365-70. [PubMed: 12145236]

43. Perry RC, Shankar RR, Fineberg N, McGill J, Baron AD. HbA1c measurement improves the detection of type 2 diabetes in high-risk individuals with nondiagnostic levels of fasting plasma glucose: the Early Diabetes Intervention Program (EDIP). Diabetes Care. 2001 Mar; 24(3):46571. [PubMed: 11289469] 
44. Ko GT, Chan JC, Tsang LW, Cockram CS. Combined use of fasting plasma glucose and HbA1c predicts the progression to diabetes in Chinese subjects. Diabetes Care. 2000 Dec; 23(12):1770-3. [PubMed: 11128350]

45. Wiener K, Roberts NB. The relative merits of haemoglobin A1c and fasting plasma glucose as first-line diagnostic tests for diabetes mellitus in non-pregnant subjects. Diabet Med. 1998 Jul; 15(7):558-63. [PubMed: 9686695]

46. Ng JM, Dawson AJ, Cox H, Atkin SL, Kilpatrick ES. New recommendations in diagnosis of diabetes mellitus from the Department of Health: comparing the old and new. Diabetic Medicine. 2010; 27(2):244-5. [PubMed: 20546274]

47. Janghorbani M, Amini M. Comparison of fasting glucose with post-load glucose values and glycated hemoglobin for prediction of type 2 diabetes: the isfahan diabetes prevention study. Rev Diabet Stud. 2009 Summer;6(2):117-23. [PubMed: 19806241]

48. Davidson MB, Schriger DL, Peters AL, Lorber B. Relationship between fasting plasma glucose and glycosylated hemoglobin: potential for false-positive diagnoses of type 2 diabetes using new diagnostic criteria. JAMA. 1999 Apr 7; 281(13):1203-10. [PubMed: 10199430] 


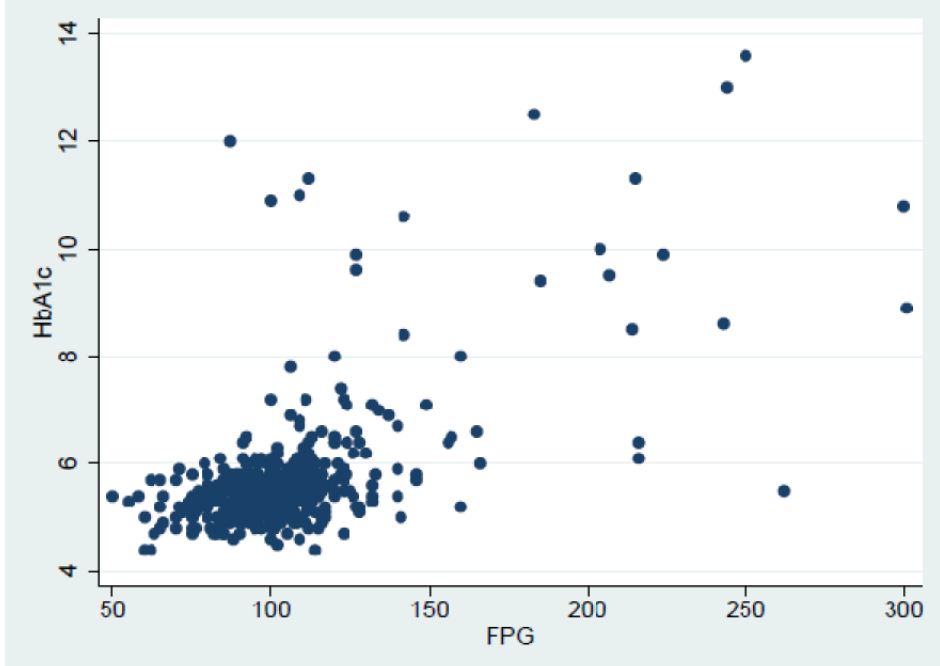

Figure-1. Correlation between $\mathrm{HbA}_{1 \mathrm{c}}$ and FPG (Pearson's correlation) 


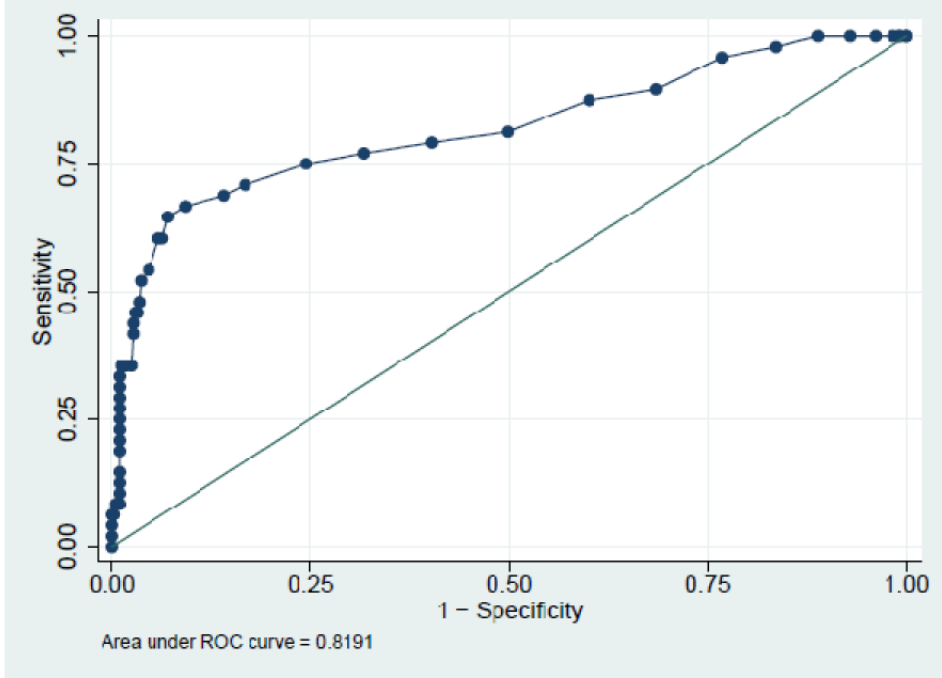

Figure - 2. Receiver Operating Characteristic Curve for diabetes using FPG $\geq 126 \mathrm{mg} / \mathrm{dl}$ criterion 
Table-1

Comparison of characteristics of population included in the study (for whom $\mathrm{HbA}_{1 \mathrm{c}}$ results were available) with those excluded from the study (for whom $\mathrm{HbA}_{1 \mathrm{c}}$ results were not available)

\begin{tabular}{|l|c|c|c|c|}
\hline \multirow{2}{*}{ Characteristics } & \multirow{2}{*}{ Overall (n=3280) } & \multicolumn{2}{|c|}{ Mean (SE) } & \multirow{2}{*}{ P-Value $f$} \\
\cline { 3 - 4 } & & Included (525) & Excluded (2755) & \\
\hline Age & $47.6(0.43)$ & $47.5(0.42)$ & $48.7(0.19)$ & 0.01 \\
\hline BMI $\left(\mathrm{kg} / \mathrm{m}^{2}\right)$ & $25.9(0.22)$ & $25.9(0.22)$ & $25.3(0.10)$ & 0.01 \\
\hline Waist circumference (cms) & $92.5(0.53)$ & $92.8(0.54)$ & $87.4(0.24)$ & $<0.001$ \\
\hline Hip circumference (cms) & $96.3(0.48)$ & $96.4(0.48)$ & $91.9(0.23)$ & $<0.001$ \\
\hline Fasting Plasma Glucose (FPG) & $115.3(1.13)$ & $113.3(1.94)$ & $115.8(1.32)$ & 0.38 \\
\hline & Proportions $(\%)$ & & P-Value \\
\hline Known diabetes & 17.4 & 12.4 & 13.9 & $<0.001$ \\
\hline IFG (ADA) & 36.5 & 44.8 & 26.2 & $<0.001$ \\
\hline IFG (WHO) & 14.4 & 18.3 & 10.2 & $<0.001$ \\
\hline NDD & 15.4 & 10.2 & 12.8 & $<0.001$ \\
\hline
\end{tabular}

SE-Standard Error; BMI-Body Mass Index (derived from height and weight and expressed as kg/m²); IFG-Impaired Fasting Glucose; NDD-Newly Diagnosed Diabetes

$f_{\text {Statistically significant difference between the two groups of participants by ttest }}$

${ }^{\#}$ Chi-square test for significant difference between the groups 
Table-2

\section{Characteristics of the study population}

\begin{tabular}{|l|c|c|c|c|c|c|}
\hline \multirow{2}{*}{ Characteristics } & \multirow{2}{*}{ Overall (n=525) } & \multicolumn{5}{|c|}{ Mean (SE) $f$} \\
\cline { 3 - 7 } & & NFG & IFG (ADA) & IFG (WHO) & NDD & Known diabetes \\
\hline Age & $47.3(.52)$ & $46.1(.54)$ & $47.5(.67)$ & $48.2(1.03)$ & $50.1(1.49)^{* * * \#}$ & $51.8(1.03)$ \\
\hline BMI $\left(\mathrm{kg} / \mathrm{m}^{2}\right)$ & $26(.25)$ & $25.4(.33)$ & $26.4(.37)$ & $27.5(0.61)^{* *}$ & $25.8(.47)$ & $26.5(0.58)$ \\
\hline Waist circumference (cms) & $92.7(.54)$ & $92(.81)$ & $93.3(.90)$ & $92.2(1.52)^{* *}$ & $90.3(2.02)^{\#}$ & $97.2(1.58)$ \\
\hline Hip circumference $(\mathrm{cms})$ & $96.5(.49)$ & $96(.73)$ & $97.6(.78)$ & $99.4(1.35)^{*}$ & $93.7(1.98)^{\#}$ & $98.6(1.34)$ \\
\hline $\mathrm{HbA}_{1 \mathrm{c}}$ & $5.9(.08)$ & $5.4(.04)$ & $5.7(.06)^{*}$ & $5.8(.09)^{*}$ & $7.5(.34)^{* * * \# \#}$ & $8.4(0.32)^{* * \# \#}$ \\
\hline
\end{tabular}

SE-Standard Error; NFG-Normal Fasting Glucose; IFG-Impaired Fasting Glucose; BMI-Body Mass Index (derived from height and weight and expressed as kg/m²); NDD - Newly Diagnosed Diabetes; ADA - American Diabetes Association; WHO - World Health Organisation

$f_{\text {Statistical association (ANOVA Prob }>\text { F) between the categories of FPG (NFG, IFG, NDD) and the continuous variables (population }}$ characteristics):

* $\mathrm{P}<0.05$,

*** $\mathrm{P}<0.01$ and

*** $\mathrm{P}<0.001$ (compared to NFG);

${ }^{\#} \mathrm{P}<0.05$,

${ }^{\#} \mathrm{P}<0.01$ and

${ }^{\# \# \#}<0.001$ (compared to IFG) 


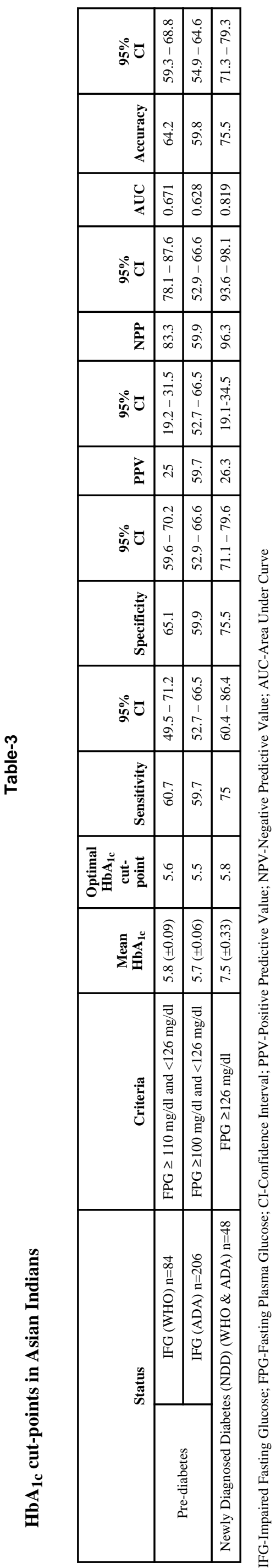




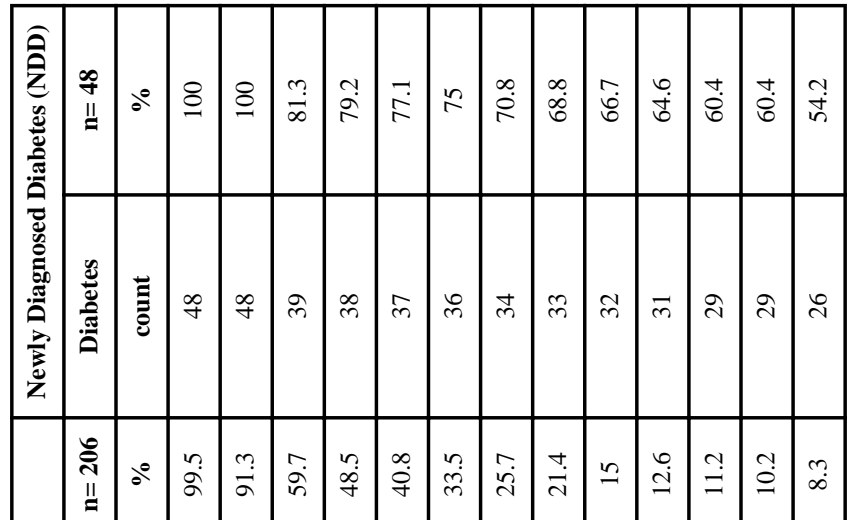

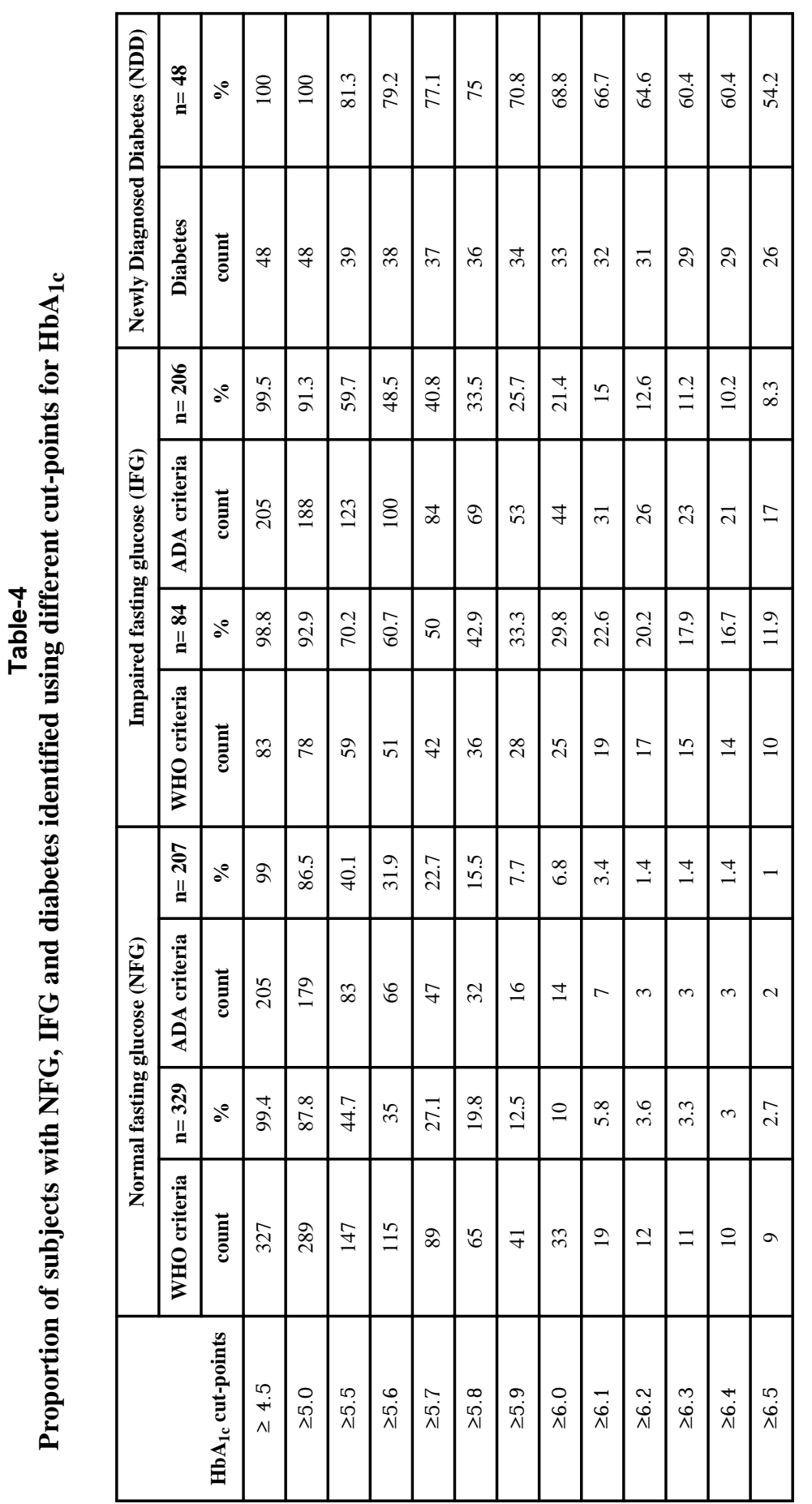

